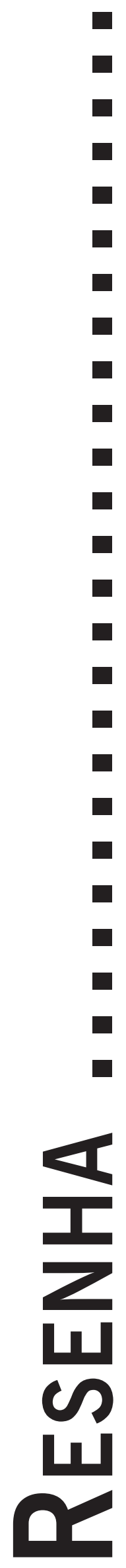




\title{
TERAPIA FENOMENOLÓGICO-EXISTENCIAL NAS COMUNIDADES POPULARES - POR UMA TERAPÊUTICA HILÉTICA E BRASILEIRAMENTE SITUADA
}

\author{
Gustavo Santos, Curitiba: Editora CRV (2015)
}

Paulo Evangelista

Gustavo Santos é professor de Psicologia na Universidade Federal do Triângulo Mineiro, onde concentra aulas e pesquisas na interface da fenomenologia com a psicologia. Atualmente está morando em Buenos Aires, onde cursa pós-graduação e escreve tese de doutorado nessa mesma área. De lá, tem apresentado aos estudiosos brasileiros a breve obra do psiquiatra e escritor espanhol Luis Martin-Santos. Também de Buenos Aires e de seus estudos em terras portenhas vem o livro que acaba de ser publicado Terapia Fenomenológico-Existencial nas Comunidades Populares - Por uma terapêutica hilética e brasileiramente situada (Curitiba: Editora CRV, 2015).

Sua proposta no livro é muito interessante e merece ser conhecida. Partindo da premissa fenomenológica de que se deve deixar os fenômenos se mostrarem por si mesmos, Santos coloca em questão a correspondência da formação em psicologia no Brasil às demandas da população brasileira. O exemplo mais claro da discrepância que o autor aponta é a formação do psicólogo para ser psicoterapeuta individual, seguindo o modelo de consultório particular, frequentemente psicanalítico, ao passo que a população precisa ser atendida em espaços públicos, em grupo, em domicílio, sem tempo e recursos para sessões semanais. Não se trata de ampliar numericamente a população atendida. Trata-se, outrossim, de conhecer o brasileiro que procura o psicólogo e desenvolver modalidades de prática psicológica que lhe sejam pertinentes.

É na fenomenologia de Husserl que Santos encontra inspiração para esse questionamento e apontamentos propositivos. Mais especificamente, encontra nas análises husserlianas da correlação intencional noético-noemática a importância da hyle, o material "sensível da experiência advindo do real, puramente sensível” (p.41) que embasa toda fenomenalização. Em termos práticos, o que o autor propõe é que a materialidade tenha tanta importância nos atendimentos psicológicos quanto a elaboração cognitiva e significativa (noética). Infelizmente, o autor não discute com abordagens terapêuticas que já lancem mão de recursos materiais, como a Gestalt-terapia e suas experimentações, e desconheça modalidades de prática psicológica como as Oficinas de Criatividade, que são terapêuticas sem serem psicoterapêuticas (p. ex., Jordão, 1999; Schmidt \& Ostronoff, 1999; Cupertino, 2008)

Os conceitos da fenomenologia de Husserl são difíceis, sobretudo para os leitores iniciantes. Mas Santos é bastante didático. Ademais, não gasta tempo nas minúcias dos conceitos de cada manuscrito da obra husserliana (isso cabe a filósofos, não a psicólogos). Assim, apresenta uma rápida síntese dos aspectos que interessam à sua proposta para fundamentar sua leitura do processo psicoterapêutico. Nisto, evidencia-se a influência do pensamento do psicólogo social argentino Alfredo Moffatt e sua "terapia de crise".

Santos relê o processo psicoterapêutico como composto por 4 etapas: 1. a queixa - interpretação naturalizante, objetiva, do sofrimento que motiva a procura por psicólogo; 2. A expressão da queixa - momento em que a queixa é assumida como acontecimento num contexto vital biográfico; 3. Demanda - quando a queixa é assumida como fenômeno, isto é, como modo de uma experiência dar-se àquele que a experiência, ou seja, que o sofrimento psicológico não é algo exterior, que advém ao indivíduo, mas que é parte de quem se é; e 4. Análise existencial - momento do processo em que o paciente desvela e assume aspectos ontológicos do existir, tais como aqueles descritos por Sartre, Kierkegaard e Heidegger.

Vale enfatizar que Santos chama esta psicoterapia de fenomenológica e existencial, pois no início se trabalham aspectos de significação de fenômenos na consciência (Fenomenologia) para, em seguida, assumir a própria existência como questão (Existencialismo). Nisso, o autor difere de uma tradição que tem ampliado seu espaço na Psicologia brasileira e da qual o autor desta resenha é participante, a psicologia fenomenológica existencial (ou fenomenológico-existencial), que lê Husserl a partir de Heidegger e encontra na analítica existencial deste as 
bases para a interpretação dos fenômenos clínicos. À luz deste olhar, a esquematização de Santos soa artificial; o que não é negado pelo próprio autor, que indica que as fases se sobrepõem, não são lineares nem evolutivas. Mas, como já mencionado, a esquematização é proposta e pode ser muito esclarecedora para estudantes e psicólogos que se iniciam nesta "abordagem".

O terceiro capítulo do livro traz a contribuição original de Santos: sua proposta de que a psicoterapia brasileira seja "brasileiramente situada", conforme o título. Isso exige que se conheça a população brasileira, ao invés de assumi-la como semelhante à europeia ou americana, que são as culturas de onde provêm as teorias psicológicas mais disseminadas nas nossas universidades.

Santos parte de uma divisão bem conhecida a todos de classes sociais na sociedade brasileira. E, seguindo Moffatt, que verifica sofrimentos psicológicos diferentes entre ricos e pobres argentinos, propõe que o mesmo aconteça no Brasil. Seu diferencial está em se perguntar quais recursos a população de baixa renda lança mão a fim de se cuidar. Por isso, traça as análises de crentes e malandros. Fica em questão se são os melhores arquétipos da população de baixa renda.

Santos extrai dessas análises elementos interessantes que sugerem modelos de intervenção psicológica. Por exemplo, verifica como nas religiões brasileiras as divindades são materializadas, antromorfizadas, tornando-se próximas e cotidianas, ganhando mais poder para intervir na dura realidade do crente. É assim na umbanda e nas crescentes igrejas universais baseadas na teologia da prosperidade. Essas religiões respondem a uma demanda da população que, se a psicologia conhece, não sabe ainda como responder. Oferecem elementos sensíveis ("hiléticos") para combater os males que afligem a população - alcoolismo, desemprego, problemas familiares -, uma comunidade de apoio e métodos claros (não individualizados, é verdade) que promovem mudanças existenciais radicais. Compare-se isso à psicoterapia psicanalítica individual em consultório para se ver o abismo entre a demanda e a oferta de serviços psicológicos. Mesmo as rodas de samba, que poderiam ser interpretadas como diversão, são consideradas por Santos modos de cuidar de si dos brasileiros.

Os malandros são personagens conhecidos do brasileiro. Carentes de proveniência, não carregam nome de família nem peso da tradição. Seu destino está unicamente em suas mãos, projetando-se ao futuro, criando-o e criando-se, aproveitando as brechas que as situações trazem. O malandro é alguém que "se vira" na vida. Não é assim que muitos brasileiros vivem? Será que a Psicologia brasileira compreende esse modo de ser? Será que nossos modelos psicoterapêuticos levam em conta essa "vocação" nacional para se virar? Ou será que teorias estrangeiras importadas sobre motivação dificultam nossa visão?

As ideias de Santos estão bem fundamentadas na literatura, mas deixam a sensação de ter caído na mesma so- fisticação academicista que questiona. A maneira mais rica e fenomenológica de apresentar sua proposta seria indo às coisas mesmas, ou seja, apresentando experiências da dimensão hilética na psicoterapia. Santos menciona muito brevemente apenas três, que não ocupam duas páginas de seu livro. Ou seja, as psicoterapias fenomenológicoexistenciais conduzidas e supervisionadas por ele é que deveriam ser o núcleo deste livro. Como está, as propostas soam teóricas demais. Bem fundamentadas, é verdade, mas ainda apartadas da vivência cotidiana do brasileiro.

Ao término da leitura, pode ficar para o leitor a mesma dúvida que pairou para este resenhista, cujo conhecimento da obra de Husserl é limitado: é possível aproximar o "hilético" do "meramente sensorial", como Santos faz? Isto é, mesmo quando se experienciam sensações não claramente significáveis - como, por exemplo, numa instalação artística de Hélio Oiticica - ainda assim não figuraria o "hilético" apenas como suporte imediatamente suplantado pela correlação noético-noemática? Sente-se algo estranho, viscoso, incômodo, etc., e nunca o "puramente" sensorial. "Estranho", "viscoso", "incômodo" já são significações. Ainda assim, esta questão teórica não retira da proposta de Santos seu valor. Os psicólogos fenomenológicos brasileiros, dentre os quais estou incluído, precisam, sim, para serem fenomenológicos, deixar que o público dos atendimentos - o fenômeno, portanto - possa ser tal como é, e não de acordo com o que dizem as teorias psicológicas a seu respeito.

\section{Referências}

Jordão, M. Oficinas em Aconselhamento: Um Processo em Andamento. In: MORATO, H. T. P. (Org.) Aconselhamento psicológico centrado na pessoa: novos desafios. São Paulo: Casa do Psicólogo, 1999.

Schmidt, M. L. \& Ostronoff, V. Oficinas de Criatividade: elementos para a Explicitação de Propostas Teórico-Práticas. In: MORATO, H. T. P. (Org.) Aconselhamento psicológico centrado na pessoa: novos desafios. São Paulo: Casa do Psicólogo, 1999.

Cupertino, C. (Org.) Espaços de criação em Psicologia: oficinas na prática. São Paulo: Annablume, 2008.

Paulo Eduardo Rodrigues Alves Evangelista - Doutor em Psicologia Escolar e do Desenvolvimento pela Universidade de São Paulo, Mestre em Filosofia e Graduação em Psicologia pela Pontifíca Universidade Católica de São Paulo. Atua como docente e supervisor clínico na Universidade Paulista (UNIP), sendo também responsável pela elaboração dos planos de ensino e de apostilas para autoavaliação dos alunos (líder de disciplina). Endereço Institucional: R. Dr. Bacelar, 1212. São Paulo - SP - CEP: 04026-002. E-mail: paulo.e.evangelista@gmail.com 